\title{
TRABALHADORES HOMOSSEXUAIS, CONTROLE DE CONVENCIONALIDADE, SUSTENTABILIDADE E DIREITOS HUMANOS
}

\author{
Breno Lucas Carvalho Ribeiro ${ }^{1}$ \\ Carolina de Souza Novaes Gomes Teixeira ${ }^{2}$
}

Resumo: A presente pesquisa baseia-se na metodologia teórica documental do tipo dedutiva, com técnicas de natureza qualitativa e análise doutrinária e legal. A partir disso, é evidente que o viés da globalização inclusiva perpassa pela concepção contemporânea do Direito Internacional do Trabalho de promover o “Trabalho Decente" em vários países membros da Organização Internacional do Trabalho (OIT). Isso ocorre por meio do combate da discriminação e do preconceito aos trabalhadores homossexuais, à promoção da igualdade de oportunidades e tratamento de gênero e raça no trabalho. Assim, em consonância com a cidadania e a inclusão como responsabilidade social, a presente pesquisa objetiva apresentar uma visão panorâmica dos Direitos Humanos, da Constituição da República de $1988(\mathrm{CR} / 88)$ e da OIT. A organização e outros membros internacionais, dessa forma, contribuíram para as conquistas advindas da Declaração de Princípios e Direitos Fundamentais no Trabalho de 1988 para o constante processo de reconhecimento e de efetivação dos direitos humanos dos trabalhadores homossexuais em âmbito internacional e para a sustentabilidade.

Palavras-Chave: Convencionalidade; Direitos Humanos; Globalização; Homossexuais.

\footnotetext{
${ }^{1}$ Graduado em Direito pela Faculdade Mineira de Direito da Pontifícia Universidade Católica de Minas Gerais (PUC-MG). Pós-Graduando em Direito Constitucional pela Universidade Cândido Mendes (UCAM). Advogado Trabalhista. Pesquisador nos institutos Retrabalhando o Direito e Instituto de Investigação Científica Constituição e Processo (PUC-MG) e Diverso (UFMG)

${ }^{2}$ Graduada em Direito pela Universidade Federal de Ouro Preto. Mestre e Doutoranda em Direito do Trabalho, Modernidade e Democracia pela Faculdade Mineira de Direito da Pontifícia Universidade Católica de Minas Gerais (PUC-MG). Professora Assistente I da Faculdade Mineira de Direito da Pontifícia Universidade Católica de Minas Gerais (PUC-MG). Advogado Trabalhista e Autora de artigos jurídicos
} 
Abstract: This research is based on the theoretical methodology of the deductive type, with qualitative techniques and doctrinal and legal analysis. From this, it is evident that the bias of inclusive globalization permepasses The contemporary conception of international labor law to promote "decent work" in several member countries of the International Labour Organization (ILO). This occurs through the fight against discrimination and prejudice to homosexual workers, to the promotion of equal opportunities and treatment of gender and race at work. Thus, in consonance with citizenship and inclusion as social responsibility, this research aims to present a panoramic view of human rights, the Constitution of the Republic of $1988(\mathrm{CR} / 88)$ and the ILO. The organization and other international members thus contributed to the achievements of the Declaration of Fundamental Principles and rights in the work of 1988 to the constant process of recognizing and effecting human rights of International and sustainability workers.

\section{Keywords:}

Conventionality;

Globalization; Homosexuals; Human rights;

\section{Introdução}

Sabe-se que, no sistema capitalista de produção, o trabalho exerce um papel importante nas relações sociais além de atuar como uma das forças constituidoras do próprio homem.

Não raro, em um mundo laboral caracterizado por incertezas, é evidente a pertinência da temática da justiça social como o objetivo amplo da regulação de relações trabalhistas em escala internacional. É certo, neste sentido, que a Modernidade legou à humanidade o substrato para a construção da ideia de um primado da proteção social, que elevou a inserção igualitária de sujeitos de direito à condição de razão de existência do econômico, do político e do jurídico.

Com o advento das chamadas sociedades contemporâneas, que fronteiras e padrões sociais são cada vez mais contestados e encontram-se cada vez mais fragmentados.

A partir do crescimento dos movimentos populares - que em diversas ocasiões foram seus parceiros nas reivindicações sociais - a organização homossexual sustentou-se no tripé: identidade, sexualidade e cidadania, buscando, principalmente, a identidade homossexual, o direito ao livre exercício 
das escolhas sexuais individuais e a autonomia do movimento.

Nesse contexto, formas de conduta com seus valores e práticas - que anteriormente se objetivava marginalizar, reduzir e ocultar, de modo a torná-las clandestinas - tornam-se a manifestar e tentam buscar o seu espaço. Movimentos anteriormente marginalizados - como o das mulheres, lésbicas, bissexuais, transexuais e gays - começam a reivindicar seu espaço social em busca de legitimação.

Irrefutavelmente, a globalização impõe aos cidadãos a necessidade de reflexão e revisão dos modelos que existiram até o momento e, que agora estão em questionamento. Esses papéis, no campo social da produção material dos indivíduos, exigem dos legisladores, dos juristas e dos operadores do direito uma abertura para a atualização dos preceitos embutidos nas relações trabalhistas e na perspectiva de um constante diálogo entre os atores sociais para o fortalecimento sobre as formas de trabalho, de contratação, de execução e de tutela introduzidas em consonância com a Declaração Universal dos Direitos Humanos (DUDH). Diante disso, tornase imprescindível enaltecer e aplicar as questões da justiça, da ética, da cidadania e do direito diante da alteração de paradigmas que a sociedade está impondo a cada dia.

É o ambiente laboral, especificamente, que se mostra como um dos espaços em que encontram manifestada a luta pela liberdade e pelo fim da discriminação no trabalho em razão da sexualidade dos membros de uma organização.

Apesar de as relações laborais, entre elas as relações interpessoais em um ambiente empresarial, tentem se afastar - na contemporaneidade - do modelo burocrático na tentativa de criação de estruturas hierárquicas mais leves e fluidas, a ideia de um ambiente organizacional neutro, impessoal e despersonalizado ainda é, lamentavelmente, algo defendido pelos gestores das organizações, sendo um valor marcante nas práticas organizacionais e nas relações interpessoais no trabalho.

Entretanto, verifica-se que essa impessoalidade e neutralidade são meras fantasias, posto que o ambiente de trabalho é, de fato, socialmente construído e é por meio dele se manifestam todas as formas de relações sociais, como, por exemplo, a 
sexualidade, o desenvolvimento das atividades técnicas e a amizade.

Para que ocorra o desenvolvimento econômico-social empresarial saudável e, paralelamente, o crescimento das capacidades cognitivas, técnicas e aperfeiçoamento do trabalhador, utiliza-se o Direito do Trabalho como forma alcançar, precipuamente, sua dimensão humana na medida em que visa garantir a sobrevivência do trabalhador, assegurando o acesso aos bens necessários para garantir-lhes uma vida conforme a dignidade humana. Igualmente, atua em favor da justiça social com o fito de promover a tutela e a promoção da dignidade humana dos trabalhadores.

$\mathrm{O}$ dilema que se procura solucionar se baseia no seguinte questionamento: em que medida os órgãos internacionais contribuem para a concretização dos direitos dos homossexuais e para efetiva aplicação das leis que os resguardam?

Neste sentido, o presente artigo visa averiguar esse grupo social vulnerável na tentativa de compreensão da discriminação de trabalhadores

\footnotetext{
${ }^{3}$ Lésbicas, Gays, Bissexuais, Travestis e
}

homossexuais sob a ótica da Constituição Federal de 1988 (CR/88), da Declaração Universal dos Direitos Humanos e do Controle de Convencionalidade.

A pesquisa se justifica na medida em que o grupo LGBT3+ carece de maior visibilidade e respeito, não apenas no âmbito laboral, como em toda sociedade.

A metodologia da pesquisa baseia-se na revisão bibliográfica, cujo método adotado será o dedutivo, com técnica qualitativa e análise doutrinária e legal. O primeiro tópico visa discutir a relação da sexualidade com a CR/88. Posteriormente, estabelece a construção da relação entre direitos humanos, trabalhadores homossexuais e a necessidade de proteção da dignidade da pessoa do trabalhador. Em seguida, se expressa acerca da temática dos direitos humanos e violações a garantias e direitos fundamentais dos trabalhadores homossexuais. No último tópico se adentrará no tema do controle de convencionalidade; direitos humanos e convenções da OIT, discutindo, principalmente, seu papel e sua relação com os direitos fundamentais. 
Finalmente, são apresentadas as considerações finais.

\section{Sexualidade e constituição de 1988}

$A b$ Initio, sabe-se que a Constituição da República, já em seu preâmbulo4, assegura o exercício dos direitos sociais e individuais; a liberdade; $\quad$ o bem-estar; $\quad$ o desenvolvimento; a igualdade e a justiça como valores supremos de uma sociedade fraterna, pluralista e sem preconceitos (BRASIL, 1988).

Igualmente consagra como objetivo fundamental da República (art. 3 , IV5): "promover o bem de todos, sem

4 "Nós, representantes do povo brasileiro, reunidos em Assemblia Nacional Constituinte para instituir um Estado Democrático, destinado a assegurar o exercício dos direitos sociais e individuais, a liberdade, a segurança, o bem-estar, o desenvolvimento, a igualdade e a justiça como valores supremos de uma sociedade fraterna, pluralista e sem preconceitos, fundada na harmonia social e comprometida, na ordem interna e internacional, com a solução pacífica das controvérsias, promulgamos, sob a proteção de Deus, a seguinte Constituição da República Federativa do Brasil"

5 "Art. $3^{\circ}$ Constituem objetivos fundamentais da República Federativa do Brasil: I - construir uma sociedade livre, justa e solidária; II - garantir o desenvolvimento nacional; III - erradicar a
241

preconceitos de origem, raça, sexo, cor, idade e quaisquer outras formas de discriminação" (BRASIL, 1988).

$\mathrm{O}$ artigo 170 do referido diploma legal, incisos VII e VIII ${ }^{6}$, se refere aos princípios programáticos da atividade econômica nacional, que a justiça social só está assegurada se respeitados, dentre outros, a redução das desigualdades regionais e sociais e a busca do pleno emprego.

Tem-se o art. $205^{7}$, que atribui ao Estado o dever de auxílio ao pleno desenvolvimento do indivíduo, em seus aspectos físico e intelectual, de igual forma quanto ao seu preparo para o regular exercício da cidadania, em sua significação, isto é, sob nenhum aspecto,

pobreza e a marginalização e reduzir as desigualdades sociais e regionais; IV promover o bem de todos, sem preconceitos de origem, raça, sexo, cor, idade e quaisquer outras formas de discriminação".

${ }^{6}$ Art. 170. A ordem econômica, fundada na valorização do trabalho humano e na livre iniciativa, tem por fim assegurar a todos existência digna, conforme os ditames da justiça social, observados os seguintes princípios: VII - redução das desigualdades regionais e sociais; VIII - busca do pleno emprego".

7 “Art. 205. A educação, direito de todos e dever do Estado e da família, será promovida e incentivada com a colaboração da sociedade, visando ao pleno desenvolvimento da pessoa, seu preparo para o exercício da cidadania e sua qualificação para o trabalho". 
o Estado brasileiro poderá furtar-se ao dever de promoção - por meio de instituições públicas e privadas - do bem de todos, incluindo-se aí as minorias sociais.

Também insta salientar os super princípios constitucionais atinentes aos direitos e garantias fundamentais que, em tese, deveriam por si só assegurar a não discriminação por orientação sexual, posto que todos - indistintamente- são iguais em relação a lei (art. $5^{\circ}$, caput, da Constituição ${ }^{8}$ ), assim como "homens e mulheres são iguais em direitos e obrigações" (Brasil, 1988), sendo-lhes, desse modo, garantidas a inviolabilidade da intimidade, da vida privada, da honra e da imagem da pessoa, assegurando o direito a indenização pelo dano material ou moral decorrente de sua violação, conforme art. $5^{\circ}, \mathrm{X}$, da CR/88.

A Constituição da República de 1988 ao elencar os direitos sociais, proíbe a diferença de salários, de exercício de funções e de critério de admissão por motivo de sexo, idade, cor ou estado civil (art. $7^{\circ}, \mathrm{XXX}$ ). Estes direitos se dirigem a todos os

\footnotetext{
${ }^{8}$ Art. $5^{\circ}$ Todos são iguais perante a lei, sem distinção de qualquer natureza, garantindose aos brasileiros e aos estrangeiros residentes no País a inviolabilidade do
}

trabalhadores, inclusive àqueles de orientação sexual diversa da do trabalhador heterossexual, haja vista que, repita-se, um dos objetivos a serem alcançados pelo Estado democrático, é eliminar qualquer forma de discriminação (Gugel, 2000)

Contudo, apesar do vasto comando legal e a interpretação que se faz acerca da norma, na prática não é isso que ocorre, minorias sociais são constantemente excluídas, como é o caso de trabalhadores gays e lésbicas que, constantemente, são marcados pela exclusão e pela opressão, vivenciando, dessa forma, a violência, o preconceito e a discriminação, principalmente, nos ambientes empresariais, corporativos e laborais.

Percebe-se que a CR/88 é a norma máxima do país e, como isso, tem seu poder de produzir discursos de que o conteúdo expresso é uma verdade em si mesma. Verifica-se, no entanto, que este é um pensamento de senso comum, que permeia cotidianamente a sociedade moderna. Esse potencial que se traduz em um discurso de verdade contido na

direito à vida, à liberdade, à igualdade, à segurança e à propriedade, nos termos seguintes $[\ldots]$ 
norma é a essência da força indutora que utiliza a legislação simbólica.

Afirma-se que as normas simbólicas servem à violação de direitos fundamentais justamente porque produzem o efeito de declarar que esses direitos existem e devem ser reconhecidos. Contudo, apesar de declaradas, as normas simbólicas se caracterizam pela baixa normatividade.

Mesmo não entrando expressamente na CR/88, deve-se considerar a atual perspectiva civilconstitucional, que insere o ser humano como centro do ordenamento, como uma das principais bandeiras levantadas pelo Estado Democrático de Direito no que se refere à garantia aos bens jurídicos fundamentais, figurados sob o rol dos direitos humanos, principalmente, visando a conquista de direitos mínimos e básicos à vida, à saúde e à liberdade.

A CR/88 traz em seu bojo norma jurídica que permite invocá-la para a proteção dos direitos de pessoas do grupo LGBT+, pois na inexistência de norma específica, é preciso utilizar-se da norma geral e de hierarquia suprema.

A CR/88, do mesmo modo que a italiana, prevê a cláusula geral de tutela da personalidade que pode ser encontrada no princípio fundamental da dignidade da pessoa humana (Lôbo, 2014, p.1).

Dito isto, percebe-se que a função simbólica desempenhada pelo ordenamento jurídico trabalhista voltado à proteção do mercado de trabalho do grupo LGBT+ aparece quando há uma "hipertrofia da função normativa enaltecimento de valores sociais (igualdade e proteção)-, em detrimento de sua eficácia prática, já que, na realidade, o que se observa é a discriminação desse no mercado de trabalho" (Neves, 2007, p. 67).

Assim sendo, no próximo tópico se abordará, em âmbito internacional, a temática da criação dos direitos humanos e sua relação com a proteção dos trabalhadores homossexuais a fim de efetivar a dignidade de sua pessoa como trabalhador.

\section{Interlocuções entre direitos humanos, trabalhadores homossexuais e a necessidade de proteção da dignidade da pessoa do trabalhador}

É necessário compreender que os chamados "direitos humanos são todos aqueles positivados no plano internacional, sobretudo, os que cuidam 
de liberdade e igualdade" (Franco Filho, 2018, p. 67). Quando esses direitos são constitucionalizados, ou seja, incorporados no ordenamento jurídico interno, esses são intitulados como fundamentais.

A tutela dos direitos humanos se estabelece sobre três suportes jurídicos, quais sejam os de proteção, os complementares e os interdependentes, estabelecidos por um critério de abrangência geográfica, quais sejam: o global $^{9}$, o regional ${ }^{10}$ e o nacional ${ }^{11}$.

Constituem um sistema de autonomia e possuem contornos próprios, com índole protetiva acentuada, voltado à salvaguarda dos direitos dos seres humanos e não dos Estados, com ampla aplicabilidade na proteção dos vulneráveis, remediando os efeitos do desequilíbrio e das disparidades. Isso corrobora a concepção dos direitos humanos como um conjunto de faculdades e instituições que formam um sistema tendente a concretizar exigências de dignidade, liberdade e igualdade humanas (Soares, 2018, p. 98).

\footnotetext{
9 No contexto internacional, na seara do direito do trabalho, a proteção à pessoa do trabalhador começou a ser alinhavada com maior nitidez no preâmbulo da Constituição da OIT, como a primeira carta internacional de direitos humanos dos trabalhadores,
}

É evidente que a formulação teórica sobre os Direitos Humanos é tarefa complexa, que exige do intérprete a sistematização de seus principais aspectos a partir de perspectivas diferenciadas de ordem filosófica, internacional, constitucional e, principalmente, trabalhista. $\mathrm{O}$ que importa, em verdade, é que esses campos do saber se ordenem a partir de um centro comum, que é a concepção de dignidade da pessoa humana, valor-fonte na contemporaneidade do Direito.

A Declaração Universal dos Direitos Humanos se expressa como princípios fundamentais da ordem jurídica internacional, sendo considerada fonte de máxima hierarquia no Direito. Ela provocou uma mudança fundamental no pensamento global, afirmando que todos os seres humanos, mas todos nascem livres e iguais em dignidade e direitos.

A vida do direito é a luta, a luta dos povos, de governos, de classes, de indivíduos. O objetivo do direito é a paz, a luta é o meio de consegui-lo. Dessa

confirmada, em 1944.

10 No âmbito regional, afloram destacadamente os sistemas europeus, americanos, africanos.

11 Fixação dos direitos fundamentais nas constituições. 
forma, para que os direitos dos homossexuais sejam convalidados e concedidos, é necessário que haja muita luta; pois para conquistá-los, a luta será constante, não sendo diferente dos demais direitos do ser humano (Ihering, 2001, p. 31).

Vivemos em um novo contexto, em que os direitos não podem simplesmente serem reduzidos às normas, nem tampouco ser concebido como autossuficiente ou como a única saída para a transformação das relações sociais. O conteúdo básico dos direitos humanos não consistiria basicamente no 'direito a ter direitos', mas no conjunto de lutas pela possibilidade de viver com dignidade, reconhecendo que todos necessitam da satisfação de conjuntos

\footnotetext{
${ }^{12}$ Joaquín Herrera Flores ao apresentar sua definição crítica dos direitos humanos, propõe uma nova redação dos primeiros parágrafos da Declaração Universal:

Preámbulo: “...reconociendo que losderechos humanos no constituyenun "ideal abstracto" que como todo horizonte se aleja a medida que nos acercamos, proclamamos que tales derechossonel conjunto de procesos que losindividuos y los grupos humanos ponenen marcha cotidianamente para acceder a losbienesexigibles para una vida digna de ser vivida"

Artículo $1^{\circ}$.- Todos los seres humanos debentenerlos instrumentos, medios $\mathrm{y}$ condiciones necesarias para poder ponerenpráctica "procesos de lucha por ladignidad humana"
}

culturalmente determinados de bens materiais e imateriais, e que estas necessidades deverão ser satisfeitas dentro de um sistema de valores e processos que estão distribuídos de forma desigual entre os seres humanos, impondo um acesso hierarquizado e restrito a estes bens. ${ }^{12}$

Seriam então, os direitos humanos, resultados sempre provisórios dos processos de luta e dinâmicas sociais para acesso a bens que garantam uma sobrevivência digna?

Verifica-se que a dignidade não está efetivada, tão somente, no mero acesso aos direitos - não basta ter direito aos direitos-, mas sim no acesso ao justo e que se generalize de forma igualitária a todos. A problemática reside não no

Artículo $2^{\circ}$.- La dignidad humana es elfin perseguido por losderechos humanos. La dignidad consiste enlaobtención de unaccesoigualitario a losbienes tanto materiales como inmateriales que se han ido consiguiendoenel constante proceso de humanizacióndel ser humano

Artículo 3.- Para conseguir lo anterior, los seres humanos en lucha por abrir procesos de dignidaddebentenerel suficiente poder individual y colectivo para exigir a lasinstituciones legislativas, tanto internacionales como nacionales, unsistema de garantías (políticas, sociales, económicas $\mathrm{y}$ jurídicas) que lespermitan disfrutar del resultado de sus luchas. A tal efecto, se declaran como garantías mínimas las que a continuación se relatan... (FLORES, 2008, p.108) 
modo em como um direito transforma-se em um direito humano, mas sim em como este obtém a garantia jurídica para ser efetivo. "A dignidade é um fim material. Um objetivo que se concretiza em dito acesso igualitário e generalizado aos bens que fazem a vida ser digna de ser vivida." (Flores, 2008, p.107) ${ }^{13}$

De forma lastimável, a exclusão e a opressão dos trabalhadores homossexuais constituem, também, uma questão de justiça social e direitos humanos. Nesse sentido, a DUDH, da Organização das Nações Unidas (ONU) (1948), na qual o Brasil está inserido, dispõe, de forma clara, que:

[...]Artigo 23. 1. Todo ser humano tem direito ao trabalho, à livre escolha de emprego, a condições justas e favoráveis de trabalho e à proteção contra o desemprego. 2. Todo ser humano, sem qualquer distinção, tem direito a igual remuneração por igual trabalho. 3 . Todo ser humano que trabalha tem direito a uma remuneração justa e satisfatória, que lhe assegure, assim como à sua família, uma existência compatível com a dignidade humana e a que se acrescentarão, se necessário, outros meios de proteção social. 4 .

${ }^{13}$ La dignidadesunfin material. Un objetivo que se concreta endichoaccesoigualitario y generalizado a losbienes que hacen que la vida sea "digna" de ser vivida. (FLORES, 2008, p.107)

14 Para aprofundamento na dimensão jurídico política do desenvolvimento sustentável e no direito ao trabalho digno,
Todo ser humano tem direito a organizar sindicatos e a neles ingressar para proteção de seus interesses (ONU, 1948, s.p.).

Diante disso, percebe-se que estes são direitos de proteção, tanto quanto o Direito do Trabalho, especialmente na necessidade de que o trabalho digno alcance a sua plenitude ${ }^{14}$. Tanto um quanto o outro o foco na pessoa humana e em sua dignidade como valor a ser preservado. A maior parte dos direitos humanos foi recepcionada pelo ordenamento jurídico brasileiro de modo a reforçar o valor da pessoa do trabalhador quanto à importância do trabalho no desenvolvimento de sua personalidade.

É preciso que ações concretas de promoção do trabalhador homossexual demandem ações conjuntas da sociedade e dos Estados. Em decorrência disso, o conteúdo formal e material do contrato de trabalho pode ser objeto de controle para que ele se adéqüe aos legítimos ideais do ordenamento jurídico.

como forma de se assegurar os direitos fundamentais intergeracionais, ver: GOMES, Magno Federici; FERREIRA, Leandro José. A dimensão jurídico-política da sustentabilidade e o direito fundamental à razoável duração do procedimento. Revista do Direito, Santa Cruz do Sul, n. 52, v. 2, p. 93-111, maio/set. 2017, p. 94-97 e 103-104. 
Desse modo, a efetividade dos direitos humanos no âmbito do Direito do Trabalho tem como resultado a efetivação dos valores da dignidade da pessoa humana e do desenvolvimento da capacidade do trabalhador. Ademais, a consecução do objetivo desse direito respaldado pela perspectiva dos direitos humanos deve refletir na edição de leis que reflitam, de fato, em garantias e salvaguardas relacionadas ao vínculo trabalhista quanto a sua aplicação.

Outro ponto digno de nota é a verificação do diálogo entre a perspectiva humana do Direito do Trabalho em consonância com os direitos e as garantias fundamentais.

Vislumbra-se que o trabalhador, antes de estar sob tal condição, é cidadão e titular de direitos sociais, reconhecendo que a condição de pessoa torna o empregado titular de direitos desvinculados ao contrato de trabalho (Almeida, 2015, p. 10).

Dessa forma, considerando que o trabalhador deve ser considerado em todas as suas dimensões, de forma indissociável entre a esfera do cidadão, da pessoa e do trabalhador, é possível afirmar que é um ser único e completo, de modo que o trabalho exerce importante função psicológica na vida do trabalhador, influenciando diretamente na integridade física e psíquica deste.

Em relação às particularidades, a história revela que o Direito do Trabalho foi conquistada por meio de lutas sociais, cujo marco primordial foi a Revolução Industrial. O Direito do Trabalho, ao contrário do direito comum, não se aplica a todas as pessoas indistintamente, contudo, apenas ao grupo de pessoas que despendem sua energia em favor de outrem para sobrevivência.

Mais do que qualquer outro ramo da Ciência Jurídica, o Direito do Trabalho tem traços marcantes: um deles é o de não servir indistintamente a pessoas difusas, cujas posições se alternam a cada instante. "Na verdade, de todos os ramos do Direito, foi o primeiro construído basicamente pelos oprimidos, que conseguiram opor obstáculos à sua própria exploração" (Viana, 2001, p. 47).

É neste sentido que a efetividade dos direitos trabalhistas colabora para o fortalecimento da democracia, pois grande parte dos cidadãos sobrevive por meio da venda da força de trabalho. Sem o cumprimento dos direitos trabalhistas não há distribuição de renda, inclusão social e melhoria da condição socioeconômica da população, o que 
viola os princípios e objetivos da República, entre eles a dignidade.

Dessa forma, o descumprimento dos direitos trabalhistas atenta contra a democracia, pois retira do trabalhador direitos que lhe foram conferidos pela Constituição da República de 1988. Nesse contexto, a concretização da $\mathrm{CR} / 88$ é falha no cumprimento dos objetivos a que se propôs de efetivação da democracia e da interpretação dos direitos e garantias dos homossexuais, porque previu direitos sociais apenas formalmente, os quais não são materialmente usufruídos por seus destinatários, em razão da inércia do Estado, garantindo, assim, a eficiência da norma.

Sob o viés dos trabalhadores homossexuais, verifica-se que, apesar dos tratados internacionais e das interpretações dos tribunais superiores acerca da proteção desse grupo, o que se percebe é a motivação, sobretudo, humana na medida em que visa protegêlos no mercado de trabalho. Contudo, a interpretação e a aplicabilidade das normas não devem abstrair da perspectiva econômica de modo que a proteção não implique um impedimento ao ingresso ou a promoção no mercado laboral, a ponto de serem preteridos.
É necessário, portanto, repensar o

Direito do Trabalho sob uma perspectiva humana. Por mais que o objetivo do capitalismo seja o aspecto meramente econômico, ao passo que esse direito se apresenta justamente como um contraponto contra hegemônico com uma perspectiva humana. É certo que, enquanto ser social e, não muito menos, por meio do trabalho, que este indivíduo se insere socialmente, enquanto condição de sobrevivência digna, de formação, desenvolvimento e sociabilidade humana (Teodoro, 2018, p. 176).

A partir disso, percebe-se que o tratamento diferenciado em razão da orientação sexual no mercado de trabalho, baseado unicamente pela questão da sexualidade, os desejáveis efeitos protetivos e emancipatórios humanos, em relação aos homossexuais, são de forma lastimável subvertidos. A possível conseqüência disso, é a intensificação da segregação dessa mão de obra no ambiente laboral - seja na ala dos desempregados ou na ala de ocupantes de empregos de baixo escalão, quando não se avalia também a perspectiva humana.

Igualmente como ocorre com as mulheres, quando se fala em Direito do 
Trabalho dos Homossexuais é preciso fazer um alerta de que certamente o tratamento dado a esses trabalhadores ainda se difere do que é dado ao trabalho dos heterossexuais, surgindo, assim, a necessidade de mecanismos compensadores das desigualdades.

Entretanto, a análise do sistema jurídico-trabalhista de proteção aos trabalhadores homossexuais demonstra que este parece carecer de efetividade, representando, em última instância, verdadeiro "teto de vidro"15, ou seja, criando um obstáculo invisível, porém rígido o bastante para evitar a ascensão profissional e salarial dos homossexuais.

Nesse sentido, os ambientes de trabalhos tradicionais ao reforçarem pressupostos equivocados de convívio, produção e divisão de tarefas, caracterizados por retratar a ideologias pré-concebidas e estereótipos nefastos, $\mathrm{o}$ Direito do Trabalho ao não interferir nessas relações acaba por perder sua efetividade, tornando-se o próprio algoz desse grupo em sua luta por igualdade jurídica no mercado de trabalho em relação aos heterossexuais.

15 Expressão utilizada por Maria Cecília Máximo Teodoro que, também, pode ser aplicada nesse contexto, conforme se verifica por meio da obra: "O Direito do Trabalho da mulher como teto de vidro no
A reprodução desta conformação social, empresarial e pública, reside num contexto em que os homossexuais almejam conquistas, principalmente no mercado de trabalho brasileiro.

O trabalho, portanto, deve ser um importante instrumento de inserção da pessoa na sociedade, que, por meio de sua função psicológica, não permite que o ser humano se dissocie do trabalho. De outro modo, é o trabalho parte da subjetividade da pessoa que trabalha, integrando a própria constituição do ser, razão pela qual a prestação do trabalho deve ser protegida. Desse modo, protegendo-se a prestação do trabalho, protege-se o próprio ser humano, porque indissociáveis.

Dito isto, se averiguará, no próximo capítulo, o controle de convencionalidade em consonância com os direitos humanos e convenções da OIT.

\section{Controle de convencionalidade; direitos humanos e convenções da OIT}

Mercado de trabalho brasileiro. In: Congresso Latino- Americano de Direito Material e Processual do Trabalho. Puc Minas. Belo Horizonte: LTr, 2017.” 
Verifica-se que os Tratados Internacionais de Direitos Humanos possuem hierarquia supralegal, conforme entendimento do Supremo Tribunal Federal (STF), estampado nos Recursos Extraordinários (RE) de $\mathrm{n}^{\mathrm{o}}$ 349703 e $n^{\circ} 466343$, que dispunham sobre a hierarquia dos tratados de direitos humanos anteriores à Emenda Constitucional (EC) $n^{\circ} 45 / 2004$, pois após essa emenda, os tratados que fossem aprovados seguindo o trâmite de uma EC passam a ser, materialmente e formalmente, CR/88 (Ventura; Pozzeti, 2014).

Em dezembro de 2008, o STF modificou parcialmente sua jurisprudência ao determinar que os tratados e convenções internacionais sobre direitos humanos têm patamar supralegal (acima das leis ordinárias e complementares). Caso sua ratificação seja feita com o quórum especial das emendas constitucionais $-\mathrm{e}$ apenas nessa hipótese -, alcançam status de EC (DELGADO, 2009, p. 231).

Diante disso, a hierarquia dos tratados internacionais no ordenamento jurídico brasileiro respeita a seguinte orientação: caso os tratados

\footnotetext{
${ }^{16}$ Todas as pessoas são iguais perante a lei e
}

250

internacionais de direitos humanos sejam aprovados com o quórum especial das Emendas Constitucionais (aprovação em dois turnos por voto de $3 / 5$ dos membros das casas do Congresso), terão status de EC; caso não sejam aprovados pelo processo legislativo das Emendas Constitucionaiss serão considerados norma supralegal. Finalmente, os tratados internacionais que não versem sobre direitos humanos ingressam no ordenamento jurídico pátrio na condição hierárquica equivalente à das leis ordinárias (Fernandes, 2008, p. 35-36).

Tratados internacionais, ratificados pelo Brasil, não indicam expressamente a eliminação da discriminação tendo como causa a orientação sexual, mas propõem a pronta e ampla extirpação de qualquer manifestação de intolerância.

Em relação ao Sistema Global de proteção dos direitos humanos, do qual a ONU é gerente, destaca-se os trabalhos da Comissão de Direitos Humanos $(\mathrm{CDH})$ do referido organismo, que, em pelo menos dois casos, reconheceu a proteção contra a discriminação prevista no artigo 26 do Pacto Internacional de Direitos Civil e Políticos ${ }^{16}$, incluindo a 
discriminação baseada na orientação sexual.

\section{Adesão do Brasil a tratados e} acordos multilaterais, que energicamente repudiam quaisquer discriminações raciais, aí compreendidas as distinções entre os homens por restrições ou preferências oriundas de raça, cor, credo, descendência ou origem nacional ou étnica, inspiradas na pretensa superioridade de um povo sobre outro.

Em âmbito regional, verifica-se o exemplo da Corte Interamericana de Direitos Humanos (CIDH), ao interpretar as cláusulas do Pacto de São José da Costa Rica, formalmente incorporado ao ordenamento positivo brasileiro (Decreto $n^{\circ}$ 678/1992), reafirmou, na linha de diversos outros instrumentos convencionais adotados no âmbito do sistema global de direitos humanos, a essencialidade do direito à identidade de gênero e à orientação sexual da pessoa humana e a indispensabilidade do respeito e da proteção estatal à convivência harmônica e ao desenvolvimento livre, digno e pleno das diversas expressões de

igual proteção da Lei. A este respeito, a lei deverá proibir qualquer forma de discriminação e garantir a todas as pessoas proteção igual e eficaz contra qualquer discriminação por motivo de raça, cor, sexo, gênero e da sexualidade, vindo a assentar, sobre tais aspectos, as seguintes conclusões:

[...] a) $\mathrm{O}$ direito à identidade deriva do reconhecimento do livre desenvolvimento da personalidade e do direito à vida privada (supra, pars. 88 e 89); b) O direito à identidade foi reconhecido por este Tribunal como um direito protegido pela Convenção Americana (supra, par. 90); c) $\mathrm{O}$ direito à identidade inclui, por sua vez, outros direitos, de acordo com as pessoas e as circunstâncias de cada caso, embora esteja intimamente relacionado com a dignidade humana, o direito à vida e o princípio da autonomia da pessoa (artigos 7 e 11 da Convenção Americana) (supra, par. 90); d) O reconhecimento da afirmação da identidade sexual e de gênero como uma manifestação da autonomia pessoal é um elemento constituinte e constitutivo da identidade das pessoas que se encontra protegido pela Convenção Americana em seus artigos 7 e 11.2 (supra, par. 98); e) A identidade de gênero e sexual está ligada ao conceito de liberdade, ao direito à vida privada e à possibilidade de todo ser humano se autodeterminar e escolher livremente as opções e circunstâncias que dão sentido à sua existência, segundo suas próprias convicções (supra, par. 93); f) A identidade de gênero foi definida neste parecer como a vivência interna e individual do gênero tal como cada pessoa sente, e pode ou não corresponder ao sexo atribuído no momento do

língua, religião, opinião política ou de outra natureza, origem nacional ou social, situação econômica, nascimento ou qualquer outra situação. 
nascimento (supra, par. 94); [...] (Unesco, 1995).

\section{Continua:}

[...] g) O sexo, o gênero, bem como as identidades, funções e atributos socialmente construídos a partir das diferenças biológicas derivadas do sexo atribuído no momento do nascimento, longe de constituir componentes objetivos e imutáveis que individualizam a pessoa, por ser um fato de natureza física ou biológica, acabam sendo traços que dependem da apreciação subjetiva de quem o detém e descansam em uma construção da identidade de gênero autopercebida, relacionada com o livre desenvolvimento da personalidade, a autodeterminação sexual e o direito à vida privada (supra, par. 95). h) $\mathrm{O}$ direito à identidade possui também um valor instrumental para o exercício de determinados direitos (supra, par. 99); i) O reconhecimento da identidade de gênero pelo Estado é de vital importância para garantir o pleno gozo dos direitos humanos das pessoas transgênero, incluindo a proteção contra a violência, a tortura, os maus-tratos, o direito à saúde, à educação, ao emprego, à moradia, ao acesso à seguridade social, bem como o direito à liberdade de expressão e associação (supra, par. 98), e j) O Estado deve assegurar que indivíduos de todas as orientações sexuais e identidades de gênero possam viver com a mesma dignidade e com o mesmo respeito a que têm direito todas as pessoas (supra, par. 100) ${ }^{17}$ (Unesco, 1995).

Desse modo, percebe-se que os princípios internacionais do Direito do

17 Em procedimento consultivo instaurado por iniciativa da República da Costa Rica
252

Trabalho, alçados à condição de Direitos

Humanos, "centralizam o homem em seu

valor maior de ser humano. Promovem, assim, uma visão humanitária dos direitos sociais, revelando o trabalho digno como direitos fundamentais universais" (Delgado, 2011, p. 65).

Mostra-se relevante destacar, também, considerado o valor incomparável da tolerância, a proclamação aprovada, em 1995, pela Conferência Geral da UNESCO "Declaração de Princípios sobre a Tolerância", que a define como "a harmonia na diferença" e como "o sustentáculo dos direitos humanos, do pluralismo (inclusive o pluralismo cultural), da democracia e do Estado de Direito" (UNESCO, 1995, s. p.), ao mesmo tempo em que adverte que "praticar a tolerância não significa renunciar às próprias convicções".

Ao contrário, um dos efeitos virtuosos dessa atitude positiva em face de terceiros, o que estimulará, naturalmente, "a aceitação e o respeito pela diversidade das pessoas, assim evitando que irrompam, no seio das formações sociais, a exclusão, a

(Parecer Consultivo OC-24/2017). 
marginalização, a violência e a discriminação contra os grupos vulneráveis, como a comunidade LGBT+" (Mello, 2019, s. p.).

Assim expõe Staffen e Santos sobre a importância da identidade entre os cidadãos e o ordenamento jurídico:

A Constituição de letra viva é aquela cujo resultado é fruto de todos os intérpretes de uma sociedade aberta. Por isso, o aspecto jurídico é apenas um dos elementos da Constituição como cultura. A aceitação de uma Constituição pressupõe normas jurídicas, mas isso não constitui, de per si, uma garantia daquilo que o Estado constitucional esteja de fato realizando, porque é preciso averiguar se há consenso em âmbito constitucional, se há correspondência entre texto constitucional e a cultura política do povo, se os cidadãos se sentem identificados com a Constituição (Stafen; Santos, 2016).

É evidente que o conteúdo filosófico dos diversos instrumentos internacionais de proteção social identificados enaltece o valor do trabalho a partir de uma perspectiva ética, com suporte na dignidade do ser humano ${ }^{18}$.

18 Em sentido equivalente: "uma política pública séria e comprometida com o bem estar da sociedade deve partir de premissas nucelares de combate à pobreza, à fome, de gerenciamento de boa saúde e bem estar. Deve prover o acesso à educação de qualidade e à igualdade de gênero, em que os indivíduos tenham acesso à água limpa e saneamento básico, energia acessível e não
Dessa maneira, é irrefutável que além do reconhecimento da importância social dos princípios de direitos humanos dos trabalhadores é preciso, igualmente, concretizá-los, viabilizando sua afirmação ética, enquanto elemento indispensável para a constituição, crescimento e realização do sujeitotrabalho.

Perpassada essa consideração, se aprofundará, especificamente, na temática da criação e do papel fundamental da OIT.

\subsection{Criação e Papel fundamental da Organização Internacional do Trabalho (OIT)}

A Organização Internacional do Trabalho foi criada pela Conferência da Paz em Versalhes em junho de 1919. Teve como objetivos promover a justiça social e, em particular, respeitar os direitos humanos no mundo do trabalho, se baseia no princípio inscrito de quenão

poluente, emprego digno e crescimento econômico, mediante projetos de inovação e infraestrutura que permitam a redução das desigualdades" (GOMES, Magno Federici; FERREIRA, Leandro José. Políticas públicas e os objetivos do desenvolvimento sustentável. Direito e Desenvolvimento, João Pessoa, v. 9, n. 2, p. 155-178, ago./dez. 2018, p. 175). 
pode haver paz universal duradoura sem justiça social.

Desde sua criação, em 1919, pelo Tratado de Versalhes, há, de modo constante, preocupação permanente em proteger o trabalhador, assegurando-lhe condições dignas de trabalho e de seguridade social.

Devido à posição central que os direitos humanos dos trabalhadores ocupam, a Declaração de 1998 enfatiza que todos os Estados-membros estão obrigados a respeitá-los, promovê-los e efetivá-los, pelo único motivo de se terem filiado à OIT e independentemente de terem ratificado as Convenções da Organização que tratam do assunto.

Desde o momento de sua instituição, a OIT vem desempenhando relevante papel na internacionalização do Direito do Trabalho, fomentando a uniformização de preceitos trabalhistas fundamentais e a sua harmonização com a ordem interna dos países celebrantes de seus Tratados e de suas Convenções (Pinto, 2014, p. 92).

Assinala-se que a OIT constitui sua razão essencial de se internacionalizar, de forma eficaz e permanente, a proteção do trabalhador, estabelecendo-se um nível mínimo de benefícios que todos os países respeitem (Gunther, 2012, p. 37).

A organização funda-se no princípio da paz universal e permanente como instrumento de concretização e de universalização dos ideais da justiça social e da proteção do trabalhador no mundo internacional do trabalho.

É uma pessoa jurídica de direito público internacional, de caráter permanente, constituída de Estados, que assumem, soberanamente, a obrigação de observar as normas constitucionais da entidade nas Convenções que ratificam, integrando o sistema das Nações Unidas como uma das suas agências especializadas.

A composição tripartida da sua assembleia geral (Conferência Internacional do Trabalho), do Conselho de Administração e de quase todos os seus órgãos colegiados, nos quais têm assento, com direito a voz e voto, representantes de Governos e de organizações de trabalhadores e de empregadores, constitui uma das características marcantes da OIT e fator de relevo na formação do alto conceito que desfruta nos planos da cultura, da produção e do trabalho (Sussekind, 2000, p. 122). 
No Brasil, destaca a atuação do órgão, mais recentemente, caracterizando-se pelo apoio ao esforço nacional de promoção do trabalho decente, principalmente, na "promoção da igualdade de oportunidades e do tratamento de gênero e de raça no trabalho e promoção de trabalho decente para os jovens" (Pinto, 2014, p. 93).

Nesse sentido, verifica-se que a "a Justiça do Trabalho é considerada um dos mais sólidos e democráticos instrumentos jurídicos e institucionais para a concretização da dignidade do ser humano e dos direitos fundamentais nos conflitos de interesse" (Rosenfeld, 2003).

A Corte Trabalhista é, portanto, um dos principais articuladores da identidade constitucional trabalhista e, fazendo uso dos recursos "linguísticos da negação, da metáfora e da metonímia, promovendo, assim, o ideal de democracia plural e inclusiva abraçado pela Constituição da República de 1988" (Santos, 2016, p. 163).

Logo, a preocupação da OIT se materializa na efetivação de políticas sociais e na busca pela promoção de um trabalho decente para todos os seres humanos, como forma de concretização dos direitos fundamentais ao trabalho e
255

como dignificação das condições laborativas ao ser humano enquanto destinatário principal de todas as ações desta egrégia organização mundial.

Analisada essa temática, neste momento, será realizado um estudo sobre a Convenção de 1988 e 111 especificamente.

\subsection{Estudos sobre a Organização Internacional do Trabalho (OIT): Análise da Convenção 111}

É mister salientar um outro documento de suma importância para o enfrentamento da discriminação no mundo do trabalho, trata-se da Convenção sobre Discriminação em Matéria de Emprego e Ocupação n 111. Essa Convenção ${ }^{\circ}$ 111, (Decreto Legislativo $\mathrm{n}^{\mathrm{o}}$ 62.150, de 19/1/68), da OIT trata da discriminação em matéria de emprego e profissão, fixa conceitos de raça, cor, sexo, religião, opinião política, ascendência nacional ou origem social (Gugel, 2000, p. 87).

É indubitável que o órgão promove normas internacionais sobre trabalho e emprego e várias delas contêm referências ou podem ser aplicadas na erradicação da homo-lesbo-transfobia. 
A Convenção 111, de 1958, inspira ações que promovem os direitos, a diversidade e a igualdade no mundo do trabalho, conforme verifica-se por meio dos $\operatorname{artigos} 1^{\circ 19}, 2^{\circ 20}, 4^{\circ 21}$ e $5^{\circ 22}$.

Como verificado, este se dá pela promoção do trabalho decente que, segundo a OIT, pode ser alcançada por meio da síntese de quatro estratégias básicas, quais sejam: $1^{\mathrm{a}}$ - garantia dos princípios e dos direitos humanos no trabalho; $2^{\mathrm{a}}$ - criação de melhores empregos e de oportunidades de melhores salários para mulheres e para

19 "Art. 1. 1 Para os fins da presente convenção o termo discriminação' compreende: a) toda distinção, exclusão ou preferência fundada na raça, cor, sexo, religião, opinião política, ascendência nacional ou origem social, que tenha por efeito destruir ou alterar a igualdade de oportunidade ou de tratamento em matéria de emprego ou profissão; b) qualquer outra distinção, exclusão ou preferência que tenha por efeito destruir ou alterar a igualdade de oportunidades ou tratamento em matéria de emprego ou profissão que poderá ser especificada pelo Membro interessado depois de consultadas as organizações representativas de empregadores $\mathrm{e}$ trabalhadores, quando estas existam, e outros organismos adequados. 2. As distinções, exclusões ou preferências fundadas em qualificações exigidas para um determinado emprego não são consideradas como discriminação. 3. Para os fins da presente convenção as palavras 'emprego' e 'profissão' incluem o acesso à formação profissional, ao emprego e às diferentes profissões, bem como às condições de emprego" (Brasil, 1968).
256

homens; $3^{\mathrm{a}}$ - extensão da proteção social;

e $4^{\mathrm{a}}$ - promoção do diálogo social.

$$
\text { Conforme o art. } 1^{\circ} \text { da convenção }
$$

111 discriminação significa:

a) toda distinção, exclusão ou preferência, com base em raça, cor, sexo, religião, opinião política, nacionalidade ou origem social, que tenha por efeito anular ou reduzir a igualdade de oportunidade ou de tratamento no emprego ou profissão; b) qualquer outra distinção, exclusão ou preferência, que tenha por efeito anular ou reduzir a igualdade de oportunidades, ou tratamento emprego ou profissão, conforme pode ser determinado pelo paísmembro concernente, após consultar organizações representativas de empregadores e

20 “Art. 2 Qualquer Membro para o qual a presente convenção se encontre em vigor compromete-se a formular e aplicar uma política nacional que tenha por fim promover, por métodos adequados às circunstâncias e aos usos nacionais, a igualdade de oportunidades e de tratamento em matéria de emprego e profissão, com o objetivo de eliminar toda discriminação nessa matéria" (Brasil, 1968).

21 "Art. 4 Não são consideradas como discriminação quaisquer medidas tomadas em relação a uma pessoa que, individualmente, seja objeto de uma suspeita legítima de se entregar a uma atividade prejudicial à segurança do Estado ou cuja atividade se encontre realmente comprovada, desde que a referida pessoa tenha o direito de recorrer a uma instância competente, estabelecida de acordo com a prática nacional" (Brasil, 1968).

22 "Art. 5 1. As medidas especiais de proteção ou de assistência previstas em outras convenções ou recomendações adotadas pela Conferência Internacional do Trabalho não são consideradas como discriminação" (Brasil, 1968). 
de trabalhadores, se as houver, e outros organismos adequados (Brasil, 1968).

A Convenção ${ }^{23} \mathrm{n}^{\mathrm{o}} 111$ - ratificada pelo Brasil ${ }^{24}$ - elenca as hipóteses em que ocorre discriminação em matéria de emprego e profissão, limita os termos "emprego" e "profissão", estabelece exceções a discriminações, ou seja, enumera hipóteses que não serão consideradas discriminatórias e regulamenta as regras de ratificação, vigência e denúncia.

$\mathrm{O}$ presente artigo visa analisar a utilização da Convenção no 111 da OIT como forma de enfrentamento a atos discriminatórios, uma vez que as sociedades modernas devem avançar em uma perspectiva de diversidade $\mathrm{e}$ garantia dos direitos fundamentais dos seres humanos.

23 Segundo Souza (2006 p. 448): “As convenções constituem tratados multilaterais, abertos á ratificação por parte dos estados membros que após tal formalidade, as regras nela esculpidas devem integrar a respectiva legislação nacional daquele Estado".

${ }^{24}$ No Brasil, foi aprovada pelo Decreto Legislativo 104 de 24.11.1964, foi ratificada em 26.11.1965 e foi promulgada pelo Decreto 62.150 de 19.01.1968, estando vigente desde 26.11.1966, sinalando-se que a convenção encontra plena receptividade e eficácia no ordenamento constitucional pátrio.

25 "Art. $7^{\circ}$ São direitos dos trabalhadores
Desse modo, a Convenção $n^{\circ} 111$ da OIT a qual é o assunto deste artigo pode ser vista como uma emenda constitucional, visto que a convenção faz parte dos convênios qualificados de fundamentais para garantir os diretos dos seres humanos no trabalho.

Em junho de 1998 o Conselho de Administração da OIT identificou oito convenções fundamentais para a garantia dos direitos humanos no trabalho, considerando estes direitos condições prévias para o desenvolvimento dos estados membros, pois proporcionam, segundo a própria OIT, um esforço para regular livremente as condições de trabalho individuais e coletivas.

Apesar de o art. $5^{\circ}$ e art. $7^{025}$ $\mathrm{XXX}^{26}, \mathrm{XXXI}^{27}, \mathrm{XXXII}^{28}, \mathrm{XXXIV}^{29}$ da $\mathrm{CR} / 88$, já terem incorporado os princípios não discriminatórios e

urbanos e rurais, além de outros que visem à melhoria de sua condição social".

26 "XXX - proibição de diferença de salários, de exercício de funções e de critério de admissão por motivo de sexo, idade, cor ou estado civil".

27 "XXXI - proibição de qualquer discriminação no tocante a salário e critérios de admissão do trabalhador portador de deficiência".

28 "XXXII - proibição de distinção entre trabalho manual, técnico e intelectual ou entre os profissionais respectivos".

29 "XXXIV - igualdade de direitos entre o trabalhador com vínculo empregatício permanente e o trabalhador avulso". 
assecuratórios dos Direitos Humanos, é certo que os Estados que ratificaram esta Convenção ficaram obrigados a revogar todas as disposições legislativas ou práticas incompatíveis com suas normas, bem como, fomentar programas educativos visando a não discriminação (Sussekind, 1998, p. 245).

No campo das relações de trabalho, a referida Convenção fixa alguns parâmetros que "facilitam o trato das questões jurídicas envolvendo o problema da discriminação no trabalho, ou, em outras palavras, da ausência de igualdade no trabalho, consagrando o princípio de não-discriminação em matéria de emprego e profissão vedando" (Sussekind, 1998, p. 358):

a) toda distinção, exclusão ou preferência fundada na raça, cor, sexo, religião, opinião política, ascendência nacional ou origem social, que tenha por efeito de obstruir ou alterar a igualdade de oportunidade ou de tratamento em matéria de emprego ou profissão e; b) qualquer outra distinção, exclusão ou preferência que tenha por efeito destruir ou alterar a igualdade de oportunidade ou tratamento em matéria de emprego ou profissão, que poderá ser especificada pelo Membro interessado depois de consultadas as organizações representativas de empregadores e trabalhadores, quando estas existam, e outros organismos adequados (Brasil, 1968).
Pode-se frisar que Estado nacional, ainda que não tenha uma legislação específica para discriminação por orientação sexual, proíbe amplamente toda e qualquer forma de discriminação que impossibilite, restrinja ou inviabilize o acesso ao mercado de trabalho. Logo, com a ratificação pelo Brasil da Convenção $\mathrm{n}^{\circ}$ 111 da OIT, o homossexual pode se valer dessa legislação protetiva contra condutas discriminatórias de empregados e colegas no âmbito do direito do trabalho.

No ambiente de trabalho, percebe-se que há, de fato, a necessidade de se constituir, conforme a OIT propõem na declaração de convenções fundamentais, que garantam os direitos humanos na relação de trabalho, principalmente nos caso específicos analisados neste artigo que se refere à discriminação. Portanto, a referida Convenção consta como fundamental para garantia dos direitos humanos, e deve ser dada atenção especial a sua real efetivação.

É nesse sentido que o trabalho constitucionalmente protegido é aquele "prestado em condições seguras, edifica identidades e atua em prol da autorrealização de cada indivíduo" 
(Santos, 2016, p. 176). É este o sentido por meio do qual o ordenamento jurídico brasileiro institui direitos trabalhistas de indisponibilidade absoluta, que asseguram as condições básicas para que o trabalho seja prestado em condições de dignidade.

Do conjunto desses direitos, o trabalho digno - exposto no diploma internacional- "não se coaduna com práticas discriminatórias e excludentes, capazes de acentuar o sofrimento que lhe é ínsito e obstar seja ele convertido em fonte de prazer, locus de estruturação da identidade e de fortalecimento dos vínculos de solidariedade humana" (Santos, 2016, p. 176).

Dito isto, inegavelmente, verifica-se que o respeito aos direitos humanos dos trabalhadores implicará a concretização dos principais objetivos da OIT que, dentre elas, é a promoção do trabalho digno e, assim, garantir que o desenvolvimento econômico seja acompanhado de um real desenvolvimento social.

\section{Conclusão}

\footnotetext{
${ }^{30}$ Considerando todas as formas possíveis de
}

Sob o exposto, verifica-se que a diversidade, inclusive a sexual, expande o repertório laboral, melhora substancialmente a qualidade das decisões no ambiente de trabalho e, igualmente, favorece e propicia o planejamento estratégico das organizações. Em conseqüência disso, não raro, ambientes respeitosos são potencialmente mais criativos, qualificados, inovadores.

$$
\text { É irrefutável o reconhecer e }
$$
valorizar o trabalhador homossexual como condição humana no empreendimento coletivo, como forma de valorização e desenvolvimento de sua subjetividade. Este é, primordialmente, um elemento decisivo para que $o$ trabalho $^{30}$ torne uma fonte de prazer, de gratificação, e, no mesmo passo, ferramenta de integração social e de sedimentação da personalidade

É certo que a cidadania assume, nesse cenário, um novo grau em relação aos objetivos do Direito, de um modo geral e, em especial, no que diz respeito à sua efetividade por meio de todos os atores sociais, seja por meio de uma melhor adaptação da legislação já

trabalho, no sentido latu sensu. 
existente ou da interpretação mais corajosa dos Tribunais trabalhistas.

Desse modo, não aceitar ou não possibilitar a plena capacidade de desenvolvimento da orientação sexual nesses espaços é negar, essencialmente, a natureza humana, e, sobretudo, violar os princípios constitucionais de igualdade e promoção do bem de todos sem qualquer preconceito que leve à discriminação.

Assim, o preconceito que gera a discriminação do grupo LGBT+, não permitindo a inclusão social é a negação total da aceitação das diferenças. A questão, entretanto, necessita de ampla discussão com a sociedade e diretamente com os movimentos sindicais das categorias de trabalhadoras(es) e de empregadoras(es) e com as comissões locais de trabalho de forma a viabilizar a negociação.

É essencial que a cultura de valorização da diversidade possa definir seu sucesso em processos de identificação, recrutamento e seleção. Também favorece o planejamento de produtos e serviços com maior criatividade e alcance em diferentes segmentos da população, além de aprimorar processos de toda ordem, incluindo a qualidade do atendimento oferecido aos clientes ou consumidores da empresa.

Não há que se falar em direitos humanos nem mesmo que se afirmar sua existência real na vida dos seres humanos sem, de fato, as normas internacionais protetivas dos trabalhadores tão bem elaboradas serem, efetivamente, respeitadas e aplicadas, o que requer de todos os obreiros atuantes e vigilantes inseridos nesta empreitada da seara justrabalhista, extrema atenção e firme determinação, porquanto tem de ser ainda mais protetiva a sua nobre missão.

Diante do exposto, o Direito do Trabalho se norteia pelo respeito à dignidade humana, uma vez que este respeito não é somente "mais um" dentre os direitos da pessoa, é, acima de tudo, o alicerce no qual se erguem os fundamentos que dão sustentação à noção de equilíbrio social e de seu ordenamento jurídico.

É imprescindível, por conseguinte, que todos os responsáveis pela construção de um novo cenário mundial reconheçam a necessidade de mudança de valores e comportamentos e tenham como objetivo maior tornar a sociedade mais justa economicamente e mais igualitária socialmente, do que 
possivelmente resultará uma globalização socialmente inclusiva.

\section{Referências}

Almeida, Cleber Lúcio de. Por um Direito do Trabalho de segunda geração: trabalhador integral e Direito do Trabalho integral. Revista do Tribunal Regional do Trabalho da $3^{\text {a }}$ Região, Belo Horizonte, v. 60, nº 91, p. 235-256, jan./jun. 2015.

Almeida, Cléber Lúcio de. A dimensão humana, social e política do Direito do Trabalho. São Paulo: LTr, 2018.

Alvarenga, Rúbia Zanotelli de. Proteção Internacional aos Direitos Humanos dos Trabalhadores: A declaração da OIT sobre Princípios e Direitos Fundamentais no Trabalho de 1988. Revista LTr, v. $81, n^{\circ} 7$, p. 1360-1393, jul. 2017. Disponível em: www.cidp.pt/revistas/rjlb/2018/3/2018_ 03_1359_1393.pdf. Acesso em: 19 mar. 2019.

Andrade, Fernanda Rodrigues Guimarães. Direitos humanos dos trabalhadores: uma análise da Declaração da Organização
Periódico do Núcleo de Estudos e Pesquisas sobre Gênero e Direito Centro de Ciências Jurídicas - Universidade Federal da Paraíba V. 8 - $\mathrm{N}^{\circ} 03$ - Ano 2019 261 Internacional do Trabalho (OIT) sobre os princípios e direitos fundamentais no trabalho. Projeto de pesquisa orientado pela Profa. Dra. Gabriela Neves Delgado e apresentado, pela aluna bolsista, ao Programa de Iniciação Científica da FAPEMIG, Belo Horizonte, UFMG, 2010.Disponível em www.oit.org.br/node/472. Acesso em: 20 mar. 2010.

Barzotto, Luciane Cardoso. Direitos humanos e trabalhadores. Porto Alegre: Livraria do Advogado, 2007.

Bauman, Zygmunt. O mal-estar da pósmodernidade. Rio de Janeiro: Jorge Zahar Editora, 1998.

Brasil. Constituição da República Federativa do Brasil de 1988. Diário Oficial da União, Brasília, out. 1988. Disponível em: http://www.planalto.gov.br/ccivil_03/co nstituicao/constituicao.htm. Acesso em: 24 fev. 2019.

BRASIL. Decreto 62.150, de 19 jan. 1968.

Brasil. Decreto $\mathrm{n}^{\circ}$ 65.910, de 9 dez. 1969.

Redistribui, com os respectivos 
ocupantes, para o Quadro de Pessoal Parte Especial - do Conselho Nacional de Telecomunicações, (CONTEL) cargos originários dos extintos Lloyd Brasileiro - Patrimônio Nacional e Companhia Nacional de Navegação Costeira Autarquia Federal e dá outras providências. Diário Oficial da União, Brasília, 22 dez. 1969. Disponível em: https://www2.camara.leg.br/legin/fed/de cret/1960-1969/decreto-65810-8dezembro-1969-407323publicacaooriginal-1-pe.html. Acesso em: 15 de mar. de 2019.

Brasil, Decreto n ${ }^{\circ}$ 592, de 6 jul. 1992. Atos Internacionais. Pacto Internacional sobre Direitos Civis e Políticos. Promulgação. Diário Oficial da União, Brasília, 7 jul. 1992. Disponível em: www.planalto.gov.br/ccivil_03/decreto/ 1990-1994/d0592.htm. Acesso em: 19 de mar. de 2019.

Cadematori, Daniela Mesquita Leutchuk De; Santos, Pablo Henrique Silva Dos. Aplicabilidade da Convenção 111 da OIT como forma de combate à discrminação no ambiente de trabalho nas decisões do Tribunal Regional do Trabalho da $4^{\circ}$ Região. In: Cecato, Maria Aurea Baroni; NUNES, Claudio
Pedrosa; MISAILIDIS, Mirta Gladys Lerena Manzo de (Orgs). Direito do Trabalho I. Congresso Nacional do CONPEDI/UFPB, 2014, Paraíba. Cap. 4, p. 62-91. Disponível em: www.publicadireito.com.br/artigos/?cod =1a8f6c02ab62ed32. Acesso em: 19 mar. 2019.

Castells, Manuel. O poder da identidade. São Paulo: Paz e Terra, 1999.

Cortina, L.M.; Wasti, S.A. Profiles in coping: responses to sexual harassment across persons, organizations, and cultures. Journal of Applied Psychology, Bethesda, v. 90, $\mathrm{n}^{\circ} 1, \mathrm{p}$. 182-192, jan. 2005.

Delgado, Gabriela Neves. Direito fundamental ao trabalho digno. São Paulo: LTr, 2006.

Delgado, Gabriela Neves. Direitos Humanos dos Trabalhadores: Perspectiva de Análise a partir dos Princípios Internacionais do Direito do Trabalho e do Direito Previdenciário. Revista do TST, Brasília, v. 77, $\mathrm{n}^{\circ}$ 3. p. 59-76, jul./set. 2011. Disponível em: https://juslaboris.tst.jus.br/bitstream/han 
dle/20.500.12178/26897/2011_rev_tst_ v077_n003.pdf?sequence=1\&isAllowed =y. Acesso em: 17 de mar. de 2019.

Delgado, Mauricio Godinho. Curso de Direito do Trabalho. 8. ed. São Paulo: LTr, 2009.

Fernandes, Mateus Beghini. Eficácia privada dos direitos fundamentais nas relações trabalhistas no Brasil. 2008. 131f. Dissertação (Mestrado em Direito do Trabalho) - Programa de PósGraduação em Direito. Pontifícia Universidade Católica de Minas Gerais, Belo Horizonte, 2008.

Franco Filho, Georgenor de Sousa. Direitos Humanos dos Trabalhadores. São Paulo: LTr, 2018.

Garcia, Agnaldo; Souza, Eloisio Moulin de. Sexualidade e trabalho: estudo sobre a discriminação de homossexuais masculinos no setor bancário. Revista de Administração Pública, Rio de Janeiro, v. 44, no 6, 1353-1377, nov./dez. 2010. Disponível em: www.scielo.br/pdf/rap/v44n6/a05v44n6 .pdf. Acesso em: 13 mar. 2019.
Gomes, Ana Virgínia Moreira. A declaração da OIT de 1998: história, mudanças e desafios. In: Gomes, Ana Virgínia Moreira; Freitas Júnior, Antônio Rodrigues (Org.). A Declaração de 1998 da OIT sobre Princípios e Direitos Fundamentais no Trabalho. São Paulo: LTr, 2014. Cap. 1, p. 19-38.

Gomes, Magno Federici; Ferreira, Leandro José. A dimensão jurídicopolítica da sustentabilidade e o direito fundamental à razoável duração do procedimento. Revista do Direito, Santa Cruz do Sul, no 52, v. 2, p. 93-111, maio/ago. 2017. Disponível em: $<$ http://dx.doi.org/10.17058/rdunisc.v2i 52.8864>. Acesso em: 21 mar. 2019.

Gomes, Magno Federici; Ferreira, Leandro José. Políticas públicas e os objetivos do desenvolvimento sustentável. Direito e Desenvolvimento, João Pessoa, v. 9, n. 2, p. 155-178, ago./dez. 2018. Disponível em: $<$ https://doi.org/10.25246/direitoedesen volvimento.v9i2.667>. Acesso em: 21 mar. 2019.

Greenhaus, Jeffrey H.; Parasuraman, Saroj; Wormley, Wayne M . Effects of 
race on organizational experiences, job performance evaluations, and career outcomes. The Academy of Management Journal, Nova York, v. 33, $\mathrm{n}^{\mathrm{o}} 1$, p. 64-86, mar. 1990.

Grisci, Carmem Ligia Iochins.; Bessi, Vânia Gisele. Modos de trabalhar e de ser na reestruturação bancária. Sociologias, Porto Alegre, v. 6, $\mathrm{n}^{\mathrm{o}}$ 12, jul./dez. 2004. Disponível em: http://dx.doi.org/10.1590/S151745222004000200007. Acesso em: 23 fev. 2019.

Gugel, Maria Aparecida. Discriminação do Homossexual nas Relações de Trabalho. In: Seminário Internacional sobre todas as formas de discriminação no Trabalho, Brasília, 15-16 maio 2000. Disponível em: www.pgt.mpt.gov.br/publicacoes/pub23 .html. Acesso em: 14 mar. 2019.

Gunther, Luiz Eduardo. A OIT e o direito do trabalho no Brasil. Curitiba: Juruá, 2012.

Hebl, M. R.; Griffith, K. H. The disclosure dilemma for gay men and lesbians: "coming out" at work. Journal of Applied Psychology, Bethesda, v. 87, $\mathrm{n}^{\circ}$ 6, dez. 2002.

Herek, G.M. Stigma, prejudice, and violence against lesbians and gay men. In: Gonsiorek, J.C.; Weinrich, J.D. Homosexuality: research implications for public policy. Newbury Park, California: Sage, 1991. p. 60-80. Disponível em: http://dx.doi.org/10.4135/97814833254 22.n5. Acesso em: 23 fev. 2019.

Ihering, Rudolf Von. A luta pelo Direito. São Paulo, Ed. Revista dos Tribunais, 2001.

Kant, Immanuel. Fundamentação da Metafísica dos Costumes. Trad. por Leopoldo Holzbach. São Paulo: Martin Claret, 2005.

Mello, Celso. Ação Direta de Inconstitucionalidade por omissão 26/DF. Disponível em: https://www.conjur.com.br/dl/leia-votoministro-celso-mello2.pdf. Acesso em: 19 de mar. de 2019.

Meyer, I. H. Minority stress and mental health in gay men. Journal of Health 


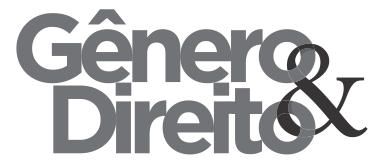

Sciences and Social Behavior, reflexões sob a perspectiva do direito

Bethesda, v. 36, p. 38-56, 1995.

Moraes, Alexandre. Direitos humanos

fundamentais: teoria geral, comentários do $\operatorname{art.}^{\mathrm{o}}$ ao $5^{\mathrm{o}}$ da Constituição da Republica Federativa do Brasil. Doutrina e jurisprudência. 9. ed. São Paulo: Atlas, 2011.

Neves, Marcelo. A constitucionalização simbólica. São Paulo: Martins Fontes, 2007.

Nicoli, Pedro Augusto Gravatá. Fundamentos de Direito Internacional Social: $\quad$ Sujeito Trabalhador, Precariedade e Proteção às Relações de Trabalho. São Paulo: LTr, 2016.

Pinto, Márcio Morena. Introdução ao direito internacional do trabalho. São Paulo: LTr, 2014.

Rosenfeld, Michel. A identidade do sujeito constitucional. Tradução de Menelick de Carvalho Netto. Belo Horizonte: Mandamentos: 2003.

Santos, Rodrigo Leonardo de Melo. A Discriminação de Homens Gays na Dinâmica das Relações de Emprego: fundamental ao trabalho digno. 2016. Tese (Mestrado em Direito)Universidade de Brasília, 2016.

Teodoro, Maria Cecília Máximo. Para repensar o direito do trabalho, sob uma perspectiva humana e econômica. São Paulo: LTr, 2018.

Teodoro, Maria Cecília Máximo. O Direito do Trabalho da mulher como teto de vidro no Mercado de trabalho brasileiro. In: Congresso Latino Americano de Direito Material e Processual do Trabalho. Puc Minas. Belo Horizonte: LTr, 2017.

Triandis, H.C.; Kurowski, L.L.; Gelfand, M.J. Workplace diversity. In: TRIANDIS, H.C; DUNNETTE, M.D.; Hough, L.M (Orgs). Handbook of industrial and organizational psychology. Palo Alto: Consulting Psychologists Press, 1994.

Trindade, Antônio Augusto Cançado. A Proteção internacional dos direitos humanos e o Brasil (1948 - 1997): as primeiras cinco décadas. 2. ed. Brasília: Universidade de Brasília, 2000. 
Unesco. Declaração de Princípios

sobre a Tolerância. Paris, 16 nov. 1995.

Disponível

em:

<www.dhnet.org.br/direitos/sip/onu/paz /dec95.htm>. Acesso em: 19 de mar. de 2019.

Silva Júnior. Arnaldo. A legislação aparente na construção de uma constitucionalização simbólica.

Disponível em <http://www.ribeirosilva.com.br/content /pdf/1410201171346.pdf>. Acesso em: 14 de mar. de 2019.

Soares, Flaviana Rampazzo. Interlocuções entre Direitos Humanos e Direito do Trabalho e a necessária proteção à dignidade da pessoa do Trabalhador. São Paulo: LTr, 2018.

Stafen, Márcio Ricardo; Santos, Rafael Padilha dos. O fundamento cultural da dignidade da pessoa humana e sua convergência para o paradigma da sustentabilidade. Veredas do Direito, Belo Horizonte, ž v. 13, ž no 26, p. $263-$ 288, maio/ago. 2016. Disponível em: $<$ http://dx.doi.org/10.18623/rvd.v13i26. 814>. Acesso em: 21 mar. 2019.

Sussekind, Arnaldo. Convenções da
OIT. 2. ed. São Paulo: Ltr, 1998.

Sussekind, Arnaldo. Direito internacional do trabalho. 3. ed. São Paulo: LTr, 2000.

Sussekind, Arnaldo. Instituições de Direito do Trabalho. São Paulo: LTr, 1996. V. 2.

Valadão, Carla Cirino. A Repersonalização do Direito do Trabalho. Disponível em: as1.trt3.jus.br/bdtrt3/bitstream/handle/1 1103/27861/A\%20repersonalização\%20 do\%20direito\%20do\%20trabalho.pdf?se quence $=1 \&$ isAllowed=y. Acesso em: 12 mar. 2019.

Zanatta, Elaine Marques. Documento e Identidade: O Movimento Homossexual no Brasil na década de 80. Disponível em: https://www.ifch.unicamp.br/ojs/index.p hp/ael/article/view/2458. Acesso em: 13 de mar de 2019 